\title{
Multilevel processes and cultural adaptation: examples from past and present small-scale societies
}

\author{
$\underline{\text { Victoria Reves-García }}^{1,2}, \underline{\text { Andrea L. Balbo }}^{3,4}, \underline{\text { Erik Gómez-Baggethun }}^{5,6}$, Maximilien Gueze $^{2}, \underline{\text { Alex Mesoudi }}^{7}, \underline{\text { Peter J. Richerson }}^{8,9}$, \\ Xavier Rubio-Campillo $^{10}$ Isabel Ruiz-Mallén $^{2,11}$ and Stephen Shennan $^{12}$
}

\begin{abstract}
The last two decades have seen a proliferation of research frameworks that emphasise the importance of understanding adaptive processes that happen at different levels. We contribute to this growing body of literature by exploring how cultural (mal) adaptive dynamics relate to multilevel social-ecological processes occurring at different scales, where the lower levels combine into new units with new organizations, functions, and emergent properties or collective behaviors. After a brief review of the concept of "cultural adaptation" from the perspective of cultural evolutionary theory, the core of the paper is constructed around the exploration of multilevel processes occurring at the temporal, spatial, social, and political scales. We do so by using insights from cultural evolutionary theory and by examining small-scale societies as case studies. In each section, we discuss the importance of the selected scale for understanding cultural adaptation and then present an example that illustrates how multilevel processes in the selected scale help explain observed patterns in the cultural adaptive process. The last section of the paper discusses the potential of modeling and computer simulation for studying multilevel processes in cultural adaptation. We conclude by highlighting how elements from cultural evolutionary theory might enrich the multilevel process discussion in resilience theory.
\end{abstract}

Key Words: cultural adaptation; cultural evolution; multilevel selection; resilience

\section{INTRODUCTION}

The last two decades have seen a proliferation of research frameworks that emphasise the importance of understanding adaptive processes that happen at different levels. The common argument in multilevel approaches, borrowed from complexity theory, is that the combination of lower level units often results in new higher level units with new organizations, functions, and emergent properties or collective behaviors that do not necessarily equal the sum of attributes observed at lower level units. As a consequence, only a multilevel approach would allow us to understand the dynamics of the nonlinear interactions between the components of these systems.

Arguments for the importance of multilevel processes have been made at different scales of analysis. For example, drawing on insights from research on biological adaptation (Fischer et al. 2009), researchers have argued that cultural adaptation cannot be fully explained at a single unit of analysis, e.g., individuals, but that we need to pay attention to the interactions of different levels of social units, e.g., individuals within a group (Waring et al. 2015). In that vein, researchers have proposed that cultural group selection is a powerful adaptive mechanism that helps explain the spread of complex social dynamics such as cooperation. Traits promoting cooperative behavior can be individually costly, but they could be selected at a group level if they generate large benefits within between-group competition (Henrich 2004, Richerson et al. 2016).

A similar argument has been made in the field of ecology, with researchers arguing that biological processes may be controlled by the scale of dominant physical processes. Thus, one needs to consider the complexity of the landscape's structure to understand and manage biological processes at fine spatial levels (Meentemeyer and Box 1987). Considerations of the multilevel spatial processes have been applied, for example, to understand the effectiveness of protected areas: The growing spatial isolation of areas devoted to conservation, which have become unconnected species' refuge surrounded by habitats with other land uses, has reduced their conservation effectiveness, because processes that take place at large scales have been neglected. Such findings have led researchers to argue that the ability of protected areas to maintain species richness and their ecological functions depends on how well they are integrated within the land use dynamics of broad-scale landscapes (DeFries et al. 2005, Laurance et al. 2012).

Political scientists have also discussed how a multilevel governance system including political actors situated at different governance levels and enmeshed in an overarching policy network can contribute to natural resource governance (Cash et al. 2006, Mwangi and Wardell 2012). Multilevel governance moves away from the debates about opposites, such as centralized versus decentralized and top down versus bottom up, to argue that effective governance needs attributes of political actors at different levels (Ostrom 2010). Ostrom defined a polycentric order as one "where many elements are capable of making mutual adjustments for ordering their relationships with one another within a general system of rules where each element acts with independence of other elements" (Ostrom 1999:57). Bali's

\footnotetext{
${ }^{1}$ Institució Catalana de Recerca i Estudis Avançats (ICREA), ${ }^{2}$ Institut de Ciència i Tecnologia Ambietals, Universitat Autònoma de Barcelona, ${ }^{3}$ Climate Change and Security (CLISEC), KlimaCampus, Center for Earth System Research and Sustainability (CEN), University of Hamburg, ${ }^{4}$ Complexity and Socioecological Dynamics (CaSEs), IMF-CSIC, ${ }_{5}^{5}$ Department of International Environment and Development Studies (Noragric), Norwegian University of Life Sciences (NMBU), ${ }^{6}$ Norwegian Institute for Nature Research (NINA), ${ }^{7}$ Department of Biosciences, University of Exeter, ${ }^{8}$ University of California, Davis, ${ }^{9}$ University College London, ${ }^{10}$ Computer Applications in Science \& Engineering, Barcelona Supercomputing Center (BSC), ${ }^{11}$ Internet Interdisciplinary Institute (IN3), Universitat Oberta de Catalunya (UOC), ${ }^{12}$ Institute of Archaeology, University College London
} 
complex irrigation system articulated around a nested hierarchy of temples (rice terrace level temples, which depend on village temples, which depend on regional temples, which in turn depend on the "Head of the Rice Terraces" temple) provides an example of adaptive multilevel governance system of a common pool resource (Lansing 2006).

In this article, we contribute to this growing body of literature by exploring how cultural adaptive dynamics relate to multilevel social-ecological processes occurring at different scales. Following Gibson et al. (2000), we define scales as the analytical dimensions used to measure and study any phenomenon and levels as the units of analysis that are located at different positions on a scale. Our contribution focuses on explaining cultural adaptation from cultural evolutionary theory perspective. We concentrated on small-scale societies to keep the level of complexity within bearable analytical limits, as opposed to large scale and hyperconnected societies, which we deem too complex for our exploration. The overall argument of the paper is that the understanding of cultural adaptation depends on our capacity to identify and describe relations between higher and lower levelunits at several scales.

\section{ON CULTURAL ADAPTATION}

Definitions of adaptation vary across disciplines, but they all capture the idea of adjustments in a system's behavior and characteristics to cope with stress or change, leading to an increased probability of reproduction or persistence (Smit and Wandel 2006, Nelson et al. 2007). Coined in evolutionary biology, the term broadly refers to the evolution of genetic or behavioral outcomes that enable organisms or systems to cope with externally and internally driven changes to survive and reproduce (Kitano 2002, Michod and Herron 2006). Adaptation refers to both the current state of being adapted and to the dynamic evolutionary processes leading to adaptation. Adaptation enhances the fitness and survival of the evolving entities.

In their analysis of the adaptive process, natural scientists have focused on biological responses to physical changes (e.g., environment, climate) and relations with other organisms (e.g., adaptations for competition over resources or mates, or hostparasite coevolution). Social scientists have extended the analysis of adaptation to the study of cultural responses to disturbance and change across social groups and levels of organization, e.g., individuals, communities, countries or regions (Adger et al. 2005, Waring et al. 2015, Richerson et al. 2016). There are differences in these processes: For example, cultural responses often have a degree of foresight or agency that is absent in the relatively blind process of genetic adaptation, although this difference is not absolute and cultural adaptation may also be quite myopic (see below and Mesoudi 2008). Despite these differences, the substantial similarities between the two approaches justify their comparison and integration within a common framework. Just as biological adaptation enhances the fitness and persistence of organisms and possibly of ecological communities, cultural adaptation can potentially enhance the fitness and persistence of individuals, households, communities, or larger societies (Berkes et al. 2002, Adger et al. 2005, Boyd et al. 2011).

Over the last 30 years, two different theories have highlighted the importance of multilevel interplay in social-ecological systems adaptation: resilience theory (Gunderson and Holling 2002) and cultural evolutionary theory (Cavalli-Sforza and Feldman 1981, Boyd and Richerson 1985, 2005). Resilience theory, or more recently the heuristic conceptual framework of panarchy, has largely advanced our understanding of the complex dynamics of multilevel processes affecting different scales (e.g., Gunderson and Holling 2002, Holdschlag and Ratter 2013). Panarchy's conceptual framework focuses on the adaptive nature of complex social-ecological systems, defined as social-ecological systems with multiple interconnected elements with the capacity to change and learn from experience. It considers that understanding the interactions of the different elements of the system at various spatial and temporal levels is needed to account for the dual, and seemingly contradictory, characteristics of stability and change. One of the most important insights of resilience theory is that adaptive behaviors observed at a given scale affect the system on other scales (Gunderson and Holling 2002, Folke 2006, Walker et al. 2006). Indeed, major failures in conservation and natural resource management (e.g., fisheries depletion, pollution, deforestation, or global warming) can be interpreted as a consequence of the inability to take into account multilevel processes and cross-scale dynamics embedded in the management of social-ecological systems (Gunderson and Holling 2002, Cash et al. 2006, Reid et al. 2006).

Cultural evolutionary theory has drawn inspiration and methods from the biological study of evolution and adaptation, emphasizing that the two systems of information transmission, i.e., genes and culture, are the intertwined components of a common evolutionary process (Cavalli-Sforza and Feldman 1981, Boyd and Richerson 1985). Just as genetic variation is passed from generation to generation with changes resulting from processes such as selection, mutation, migration, and drift, cultural evolutionary theory conceptualizes cultural change as a process of "descent with modification": Cultural variation is transmitted via social learning from one generation to the next via vertical or oblique cultural transmission, as well as within generations via horizontal cultural transmission, with changes resulting from processes such as cultural selection, mutation (or innovation), drift, and migration. Much attention has focused on transmission biases such as conformity or prestige bias, which have no clear parallel in genetic evolution. A major innovation of cultural evolutionary theory is in linking individual-level and population-level processes using formal mathematical models, lab experiments, field studies, and "cultural phylogenetics" studies to understand the population-level dynamics generated by the aggregation of individual-based processes of social learning (Boyd and Richerson 1985).

Within cultural evolutionary theory, adaptation has broadly the same meaning as in biology, describing the process(es) by which a cultural system becomes better fit to its environment, thereby enhancing survival and persistence. The relationship between biological and cultural adaptation can be a subtle one: The human cultural system as a whole can be seen as a biological adaptation, one that was selected as a way to deal with environments where change is too fast to be handled by pure biological evolution through natural selection of the genotype. Consequently, cultural adaptations are likely to be biologically adaptive most of the time, but not always, because of the two evolutionary systems being partially decoupled. It is also important to note that, just as biological evolution does not 
always result in biological adaptation, cultural evolution does not inevitably result in cultural adaptation. Many studies have examined how several cultural traits without an impact on fitness, i.e., neutral traits, exhibit variation because of nonselective stochastic processes (e.g., baby names and pottery decorations, see Bentley et al. 2014). In other cases, cultural traits may be functional but cultural adaptation fails to occur because of extrinsic factors, such as a reduction in population size (the Tasmanian effect: Henrich 2004) or myopic psychological biases (see below).In what follows, we use insights from cultural evolutionary theory and examples driven from small-scale societies to discuss the importance of multilevel processes at temporal, spatial, social, and political scales for understanding cultural adaptation.

\section{THE TEMPORAL SCALE}

The analysis of the tempo of cultural change has provided important insights in our understanding of cultural adaptation. First, culture is an inheritance system because it allows individuals to transmit knowledge, skills, and other learned information, but unlike genes, culture can potentially be acquired from anyone in a person's social network. Cultural evolutionary scientists have devoted much effort to the analysis of social learning, concluding that different transmission pathways (an individual-level dynamic) impact differently the rate of cultural change (a population-level process), and therefore the adaptive process (Henrich and Boyd 1998). For example, all else being equal, transmission among peers leads to more rapid cultural change, and potentially to cultural adaptation, than transmission from parents to offspring (Cavalli-Sforza and Feldman 1981, Herrmann et al. 2013). Results from agent-based simulations also suggest that interaction of cultural copying rates, innovation rates, and resource variance can lead to maladaptive outcomes (Whitehead and Richerson 2009, Lake and Crema 2012). In sum, cultural evolutionary theory suggests that the pathway chosen to transmit information between individuals is linked to the tempo of cultural adaptation of the group.

A second insight of the tempo of cultural adaptation focuses on psychological biases that occur at the short time scales, like a generation, but have consequences at multigeneration time scales. As befits a basically adaptive evolutionary system, unsystematic microdecisions might result in long-term highly adaptive practices (Smith and Winterhalder 1992) or prevent optimal long-term adaptation. For example, prestige bias related to consumerism, temporal discounting biases, where people prefer small, immediate payoffs to larger, delayed payoffs, or the planning fallacy, where people unrealistically focus on positive outcomes of their actions, can all result in maladaptive evolution (Mesoudi 2008, Smith and Winterhalder 1992) precisely because there is a misfit between the results of the individual short-term adaptive process and the group long-term adaptive process. The idea that rather myopic short-time scale adaptive processes may not generate long-term adaptation is well exemplified by the dynamical models of historical cultural change presented by Turchin (2003). Turchin modeled the rise and fall of agrarian empires as a consequence of changing levels of within-group cooperation and between-group conflict. In young, relatively small-scale empires, skilled elite classes may be beneficial to the society because of their leadership or expertise. As empires grow, elite overproduction and exploitation create a burden within the society, reducing within-group social cohesiveness and cooperation. Neighboring rival groups with smaller or no elite classes, and thus greater within-group cooperation, can then successfully invade and conquer the larger but internally divided empire. The new empire then forms an elite class, which grows, followed by invasion by a new, less internally corrupt small-scale neighbor, and the cycle continues. At play in this example are psychological biases such as the lack of elite's foresight or planning and runaway prestige hierarchies causing elite overproduction.

Third, the investigation of the tempo of cultural evolution also points to cases of complex evolutionary dynamics in which nonlinear processes cause path dependency, cycling, and chaotic variation. Such dynamic is exemplified in Bettinger's (2015) study of subsistence intensification in aboriginal Western North America. In the late Holocene, the intensified use of laborintensive plant resources and fisheries substantially raised population densities and with them the potential for conflict. Through time, the political system evolved in what Bettinger calls "orderly anarchy," a system characterized by the existence of a series of institutions (i.e., customary law, shell bead money, and shunning) that kept violence to a minimum and allowed individuals to cooperate in trade, fish weir construction, and other enterprises. The complex system of institutions was an alternate end-point solution to the paradox that an increase on population density simultaneously generated (1) increased returns from cooperative enterprises (e.g., trade) and (2) higher betweengroups conflict. As Bettinger remarks, the initial points in the organization of this system were pre-existing patrilineal kinship systems to organize defense and other forms of cooperation. Therefore, the organization of this complex system in fact shows the importance of path dependency.

In sum, cultural evolutionary theory does not only allow us to understand why our complex, cumulative culture evolved in the Pleistocene (Perreault 2012, Richerson and Boyd 2013) and compare the rates of cultural change to biological change (Henrich 2001). Such theory also equips us with insights to understand the possible tradeoffs between rather myopic shorttime scale adaptive processes and long-term adaptation.

\section{THE SPATIAL SCALE}

Societies being geographically constrained, the spatial dimension of cultural adaptation is closely related to the environment within which they are embedded (Meentemeyer and Box 1987). It is worth noticing that the spatial structure of any given society is neither uniform nor random, being affected by factors such as the uneven distribution of natural resources and by variations in phenomena that operate at more than one spatial level and that are responsible for energy inputs and external disturbances (Markofsky et al. 2016). Spatial occupation is also patterned by multiscalar interactions within and between social groups, such as competition, cooperation, or exploitation (Carballo et al. 2014). Therefore, the identification of spatial patterns in social phenomena can help us explain the cultural adaptive process as related to interactions that occur at different spatial levels (Cumming et al. 2006), an undertaking eased by emerging techniques from spatial statistics (Parker et al. 2003, Fotheringham et al. 2010). 
The case of the diffusion of agriculture (Neolithization) to Europe highlights the importance of looking at the multilevel spatial dimension of cultural adaptation. The Neolithization process represents one of the most recent cultural evolutionary shifts in human history, leading to the virtually global transition from foraging to farming economies observed over the Holocene (Mazoyer and Roudart 2006, Skoglund et al. 2012). Because there is no evidence for a global organization leading such transition, understanding the processes resulting in the Neolithic transformation depends on our capacity to connect and compare different spatial dimensions of analysis.

At the coarser geographic (and temporal) scale and within the climatic framework of the Holocene, a general overview suggests the Neolithization process was a steady global phenomenon of cultural adaptation associated with an increase in human fertility (Bocquet-Appel 2011). However, a finer grained analysis at the continental and local scales suggests that Neolithization was far from "smooth." For example, the transition to agriculture in Europe seems to have been characterized by boom-and-burst population patterns, possibly constrained by environmental and climate-related dynamics or induced by endogenous factors such as rapid population growth and unsustainable farming (Shennan et al. 2013). Furthermore, there is evidence of different Neolithic traditions, or strategies adapted to specific environmental and climatic settings. For example, two traditions are associated to the main routes for the spread of the Neolithic from Southwest Asia into Europe: The continental tradition is associated with a settlement and land use strategy primarily based on agriculture, whereas the Mediterranean tradition is associated with mixed strategies largely based on nomadic and seminomadic pastoralism (Angelucci et al. 2009). Moreover, within these broad core areas, a multiplicity of genetic, cultural, and social-ecological groupings have been recognized and described at the local levels, mediated by specific climatic, environmental, social, and cultural settings (Barker 2006).

In spite of, and perhaps thanks to, the multiple continental, regional, and local expressions of the Neolithization process, domestication and agriculture became a global phenomenon over a relatively short period of time. A key feature of early Neolithic small-scale societies that may help explain the success of this adaptive strategy is the strong coupling between the emergence of agriculture and that of increasingly complex exchange and trade networks (Ibáñez et al. 2015). Overlooked in the literature when compared with the study of agricultural developments in the domestication process, trade and exchange networks have contributed to the overall cohesion of myriads of different smallscale societies across extended regions. Through trade and exchange, local social-ecological systems and solutions, farming based and not, were embedded within the broader Neolithic context. By increasing interaction, denser linkages contributed to raising the circulation of social and cultural-technological solutions. Such geographical connectedness has now grown beyond geographical and physical boundaries, imposing new challenges for the management of different resources and for the integration of small-scale societies embedded through multilevel processes.

\section{THE SOCIAL SCALE}

Humans are adapted to social life in groups following a variety of organizational forms (Gowdy and Krall 2013). Social structures operate at many levels, e.g., families, neighborhoods, villages, clans, ethnic groups, nations, etc. Moreover, social organization levels display a large diversity in terms of structure, social norms, and interaction. In addition, these varying layers of social interaction are often nested (Coultas 2004).

Cultural evolutionary theory has studied how groups and organizations change as they solve collective action problems (Choi and Bowles 2007, Boyd and Richerson 2009). One of the more important insights of this theory has been that innovations can spread in a metapopulation despite being individually costly if the resulting new behavior increases the fitness of the group, including adaptations to environmental or other conditions (Bowles et al. 2003, Richerson et al. 2016). Thus, groups can evolve to solve social dilemmas through the creation of sanctioning norms and punishment of noncooperative individuals (Fehr and Gächter 2002). The same process could operate at a different scale, with metagroups punishing noncooperative groups, which implies that phenomena occurring at any one social level are affected by mechanisms occurring at lower and higher levels, with lower level phenomena potentially reacting to higher level phenomena and acting to change them (Waring et al. 2015).

To explore the importance of looking at multilevel social processes when dealing with cultural adaptation, we examine the case of traditional knowledge systems. Traditional knowledge systems are defined as "a cumulative body of knowledge, practice and belief evolving by adaptive processes and handed down through generations by cultural transmission, about the relationship of living beings (including humans) with one another and with their environment" (Berkes et al. 2000:1252). Researchers have argued that some of the adaptations that explain the expansion of our species are at least partially cultural; in other words, they are cumulative and transmitted by social learning (Boyd and Richerson 1985, Henrich and Boyd 1998). Groups create and transmit a set of behavioral strategies and knowledge that allow them to solve adaptive problems such as producing food, mating, investing in offspring, or managing social interactions (McDade et al. 2007, Quave and Pieroni 2015). Furthermore, it has been argued that such knowledge systems contribute to mediate people's capacity to cope with socialecological change and guide decision making regarding natural resource management and biodiversity conservation practices (Colding et al. 2003, Berkes et al. 2007).

The study of traditional ecological knowledge systems and how they affect cultural adaptation requires a multilevel approach. Several characteristics of traditional knowledge systems should be considered at the group level. For example, processes such as the creation, transmission, storage, or maintenance of knowledge rely on social efforts over time (Richerson and Boyd 2005, Smith et al. 2008). Furthermore, like other types of knowledge, traditional knowledge is a public good or a shared resource from which every member of a group may benefit, regardless of whether or not they personally contribute to its provision (Olson 1965). However, because of its level of sophistication, traditional knowledge is costly to acquire (Gurven et al. 2006) and to transmit (Demps et al. 2012). For example, research suggests that huntergatherers' acquisition of adult-level hunting competence is not only limited by the constraints of physical capital or body size, but also because the costly investment required for proficient hunting might take many years to develop after achieving adult 
body size. Understanding the individual costs associated with the acquisition of knowledge is important because it means that, given the choice between several knowledge systems, people might make selective decisions in terms of the type of knowledge they want to accumulate (Sternberg et al. 2001). Such individual decisions, however, affect higher levels, which might explain the current trend in the loss of traditional knowledge that many smallscale societies are experiencing (Reyes-García et al. 2013).

The analysis of multilevel social interactions also reveals patterns in how social knowledge dynamics relate to cultural adaptations. If there were no multilevel interactions and individuals acted only to optimize their survival strategies, one would expect that individual levels of traditional ecological knowledge would correlate with individual fitness. However, under a multilevel framework one should expect to see social behavior evolve when selection operates at social levels higher than the individual: Behaviors that bring benefits to the group are favored by group selection, even when they are costly for the individual (Gintis 2000, Fehr et al. 2002). This intuition is put forward from results of recent research among three forager societies. In such research, Reyes-García et al. (in press) found that variations at individual levels of traditional knowledge relate to individual hunting productivity and self-reported health, but not to nutritional status (a general proxy for individual adaptive success). The authors interpret the finding in the context of the pervasiveness of sharing in such societies: By sharing resources and knowledge, individuals who achieve higher returns to their knowledge transfer material and nonmaterial resources to the rest of the group. Thus, the use of a multilevel framework allows interpreting sharing as an adaptive mechanism that increases group fitness through the redistribution of resources (see Fischer et al. 2009 for a similar argument in biology).

\section{THE POLITICAL SCALE}

Individuals engage in a wide diversity of activities in their daily lives, with a series of informal and formal institutions affecting their decisions at any point of time. Governance refers to the set of rules that specifies who can make decisions in a given context, what aggregation rule will be used in making decisions, and how information and payoffs will be distributed in these processes (Bache and Flinders 2004). As different decision agents (i.e., local, national, and international organizations, or regional and national governments) focus on different spatial and temporal scales and as different actors can be aggregated at various levels, typically related to territoriality, governance should also be analyzed from a multilevel perspective. Multilevel governance pays attention to the relations (i.e., power, contestation, learning) among political actors at different levels and how the linkages between higher and lower levels of governance institutions negatively or positively affect the decisions of political actors at different levels (Armitage 2007, Brondizio et al. 2009).

The concept of multilevel governance emphasizes the dispersion of decision making away from a central authority upward to the supranational level, downward to subnational jurisdictions, and sideways to public/private networks (Bache and Flinders 2004). The concept, originally proposed in relation to international policy, has been used to describe the complex politics of scale of environmental issues. The concept is particularly useful when dealing with environmental issues because local systems of biodiversity use and management usually consist of informal or customary institutions embedded in larger formal regulatory frameworks that go from the local to the international scales (Mwangi and Wardell 2012). As an example of multilevel governance in natural resource management, we discuss here the case of the governance of a protected areas overlapping with an indigenous territory, where national formal regulatory frameworks for the management of natural resources interact with informal or customary institutions.

The Tsimane' are an indigenous semiautarkic society in the Bolivian Amazon (Huanca 2008). Like other small-scale societies (Berkes et al. 2000, Dietz et al. 2003), the Tsimane' seem to rely on a series of flexible informal institutions (i.e., strong norms of sharing and cooperation) to deal with environmental uncertainty and unpredictable resource availability (Fernández-Llamazares et al. 2016). Such informal rules have allowed them to sustaining their livelihoods and maintain the forest with no centralized governmental control. However, since the 1970s, the Bolivian government followed international trends aiming to conserve biodiversity and established several protected areas in the Tsimane' ancestral territories. The government imposition of a strong regulatory framework, enforcement mechanisms, and sanctions triggered during the 1990s a series of protests by indigenous peoples that resulted in a more inclusive national conservation policy (Reyes-García et al. 2014). Such is the origin of the Pilón Lajas Biosphere Reserve and Indigenous Territory, where in 1992 a comanagement arrangement was instituted to involve customary institutions in decision making about the protected area (Bottazzi and Dao 2013). The novelty of the comanagement approach was that it instituted the sharing of responsibility in resource management between government agencies and local communities. At a short-term scale, such an approach promoted the coordination of activities (i.e., cocoa development projects, community-based monitoring) to deal with immediate threats such as illegal logging and colonists' encroachment. The success of some strategies, however, has been undermined by the weakening of indigenous collective action. For example, to increase the effectiveness of local monitoring and to improve forest management, the government has granted a concession for timber extraction to one of the communities in the protected area. Although the government envisioned optimistic outcomes and increased community cooperation, the concession led to an increase in deforestation by individual indigenous peoples acting in self-interest because peer sanctions had been eroded (Ruiz-Mallén et al. 2015).

Two important points can be derived from the example above. First, the analysis of multilevel governance allows spotting feedback loops between political actors operating at different levels. Thus, national policies have a clear impact on local institutions, but those in turn can also mobilize to affect national policies. Second, the analysis of interactions between political actors operating at different scales highlights how adaptive management strategies are challenged by interest, decision making, and power between institutions at different levels. In our example, the two main political actors involved (i.e., the indigenous communities and the state) operate at different temporal and spatial scales, which results in different motivations. Indigenous peoples might feel their rights to land and resources are threatened, which explains their myopic behavior in resource 
extraction. The government, in turn, might act under a longer term perspective, often pushed by international conservation norms.

\section{MODELING MULTILEVEL PROCESSES IN CULTURAL ADAPTATION}

The examples presented above provide an account of the complexity of processes that operate in different aspects of cultural (mal)adaptation across scales and within levels. Within cultural evolutionary theory, such multilevel processes have been explored using formal modeling with a diversity of techniques, such as game theory (Gintis 2000), analytical models (CavalliSforza and Feldman 1981, Boyd and Richerson 1985), and computer simulations (Kohler and Gummerman 2001). Some of these models are purely theoretical (e.g. exploring a particular mechanism, such as conformity; Henrich and Boyd 1998), whereas others use real data to explore the plausibility of a particular model tested against evidence (e.g., Bentley et al. 2014). Modeling techniques for past small-scale societies have been explored by Costopoulos and Lake (2010), Lake (2014), and Wurzer et al. (2015).

The study of multilevel processes in cultural adaptation presents important challenges that differ from those found when exploring the same question at a single level. For example, the study of multilevel processes forces researchers to combine bottom-up and top-down perspectives (Lansing 2003) and to explore potential feedback loops (Liu et al. 2007). This type of dynamics might generate nonlinear behavior, a property of complex adaptive systems (CAS; see Holland 1992). New and old formal methods used to explore CAS are well suited to explore multilevel processes in cultural adaptation. For example, classical integrodifferential and difference equations allow for the exploration of scenarios for studying population dynamics, or they can also be used to test theory against evidence with numerical methods (e.g., Kandler et al. 2010). The low dimensionality of such models is useful when fitting historical and archaeological data, which are seldom rich enough to fit complex models. Game theoretical approaches have been traditionally used for studying adaptive processes when strategic interactions are important (Smith 1982), and can be also potentially be adapted to explore multilevel dynamics (Fletcher and Zwick 2007). Statistical and stochastic models are increasingly popular ways to introduce heterogeneity into a population-based system. Using techniques such as Monte-Carlo methods allows the researcher to link stochastic models of individual behavior to population-level patterns (Traulsen and Nowak 2006). Finally, agent-based models (ABMs) are well suited for exploring the emergence of macrodynamics from microbehavior in spatially explicit heterogeneous environments. The flexibility provided by this technique allows modeling any type of interaction inside social-ecological systems, breaking the walls of multilevel analysis and correlation between different levels of adaptations.

Given the diversity of tools, researchers should carefully consider their different requirements when making a choice. For example, although equations solved with analytical approaches are better able to explain the dynamics of the system, their application to spatially structured data is difficult to achieve. For their part, ABMs are particularly difficult to understand, analyze, and replicate. Finally, the exploration of multilevel processes in cultural adaptation ultimately needs to test theoretical models against evidence using statistical data analysis. In this context, the field would benefit from applying recent developments regarding model selection frameworks able to quantify the quality of competing models, both in terms of goodness of fit and complexity.

\section{CONCLUSION}

Like resilience theory, cultural evolutionary theory highlights that a number of processes may drive cultural change and that a full understanding of this cultural change requires a proper consideration of multilevel interactions. Given this overlap, we argue that insights from cultural evolutionary theory about how multilevel processes operate might contribute to resilience theory so as to strengthen its exploration of social-environmental changes. For example, the concept of social-ecological systems could be enriched with considerations of culture as a cumulative and collective inheritance system because understanding the functioning of this system seems to relate to social adaptation, as shown in our discussions on how psychological biases occurring at one specific time frame may potentially prevent optimal longterm decision making. Similarly, understanding culture as a nonlinear process showing boom-and-burst adaptive patterns because of external forcing (in the Neolithic but also in presentday marked-based economies) as well as unsustainable (maladaptive) decisions could help untangle "persistence and change" in social-ecological systems. Moreover, as the example of the Neolithic suggests, understanding how cultural transmission operates and its relation to the spread of adaptive and maladaptive processes (time-wise and space-wise) can also help explain global, or large-scale, transitions. At a methodological level, the large experience of cultural evolutionary theory with modeling and simulations could also contribute to the formal modeling of social-ecological resilience. Although this paper is just an initial effort to bring insights from cultural evolutionary theory to resilience theory, we see much scope for integration and cross-fertilization of research findings.

Responses to this article can be read online at: http://www.ecologyandsociety.org/issues/responses. $\mathrm{php} / 8561$

\section{Acknowledgments:}

This paper resulted from discussions at the ICREA Workshop "Small-Scale Societies and Environmental Transformations: Coevolutionary Dynamics" funded by ICREA Conference Awards. $V R G$ acknowledges financial support from ERC grant agreement No. FP7-261971-LEK and from the CONSOLIDER SimulPast Project (CSD2010-00034). ALB worked on this paper on a contract from the Juan de la Cierva Programme (JCI-2011-10734, MICINN-MINECO, Spain) and on a research fellowship from The Alexander von Humboldt Foundation. This work contributes to the ICTA Unit of Excellence (MinECo, MDM2015-0552).

\section{LITERATURE CITED}

Adger, W. N., K. Brown, and E. L. Tompkins. 2005. The political economy of cross-scale networks in resource co-management. 
Ecology and Society 10(2):9. [online] URL: http://www. ecologyandsociety.org/vol10/iss2/art9/

Angelucci, D. E., G. Boschian, M. Fontanals, A. Pedrotti, and J. M. Verges. 2009. Shepherds and karst: the use of caves and rockshelters in the Mediterranean region during the Neolithic. World Archaeology 41:191-214. http://dx.doi.org/10.1080/00438240902843659

Armitage, D. 2007. Governance and the commons in a multi-level world. International Journal of the Commons 2:7-32. http://dx.doi. org/10.18352/ijc. 28

Bache, I., and M. Flinders. 2004. Multi-level governance. Oxford University Press, Oxford, UK. http://dx.doi.org/10.1093/019925$\underline{9259.001 .0001}$

Barker, G. 2006. The agricultural revolution in prehistory. Oxford University Press, Oxford, UK.

Bentley, R. A., M. J. O’Brien, and W. A. Brock. 2014. Mapping collective behavior in the big-data era. Behavioral and Brain Sciences 37:63-76. http://dx.doi.org/10.1017/S0140525X13000289

Berkes, F., M. K. Berkes, and H. Fast. 2007. Collaborative integrated management in Canada's north: the role of local and traditional knowledge and community-based monitoring. Coastal Management 35:143-162. http://dx.doi.org/10.1080/089$\underline{20750600970487}$

Berkes, F., J. Colding, and C. Folke. 2000. Rediscovery of traditional ecological knowledge as adaptive management. Ecological Applications 10:1251-1262. http://dx.doi.org/10.1890/1051-0761 (2000)010[1251:ROTEKA]2.0.CO:2

Berkes, F., J. Colding, and C. Folke, editors. 2002. Navigating social-ecological systems: building resilience for complexity and change. Cambridge University Press, Cambridge, UK. http://dx. doi.org/10.1017/cbo9780511541957

Bettinger, R. L. 2015. Orderly anarchy: sociopolitical evolution in aboriginal California. University of California Press, Berkeley, California, USA.

Bocquet-Appel, J.-P. 2011. When the world's population took off: the springboard of the Neolithic demographic transition. Science 333:560-561. http://dx.doi.org/10.1126/science.1208880

Bottazzi, P., and H. Dao. 2013. On the road through the Bolivian Amazon: a multi-level land governance analysis of deforestation. Land Use Policy 30:137-146. http://dx.doi.org/10.1016/j. landusepol.2012.03.010

Bowles, S., J.-K. Choi, and A. Hopfensitz. 2003. The co-evolution of individual behaviors and social institutions. Journal of Theoretical Biology 223:135-147. http://dx.doi.org/10.1016/ S0022-5193(03)00060-2

Boyd, R., and P. Richerson. 1985. Culture and the evolutionary process. University of Chicago Press, Chicago, Illinois, USA.

Boyd, R., and P. Richerson. 2005. The origin and evolution of cultures. Oxford, Oxford University Press.

Boyd, R., and P. J. Richerson. 2009. Culture and the evolution of human cooperation. Philosophical Transactions of the Royal Society B: Biological Sciences 364:3281-3288. http://dx.doi. org/10.1098/rstb.2009.0134
Boyd, R., P. J. Richerson, and J. Henrich. 2011. Rapid cultural adaptation can facilitate the evolution of large-scale cooperation. Behavioral Ecology and Sociobiology 65:431-444. http://dx.doi. org/10.1007/s00265-010-1100-3

Brondizio, E. S., E. Ostrom, and O. R. Young. 2009. Connectivity and the governance of multilevel social-ecological systems: the role of social capital. Annual Review of Environment and Resources 34:253-278. http://dx.doi.org/10.1146/annurev.environ.020708.100707

Carballo, D. M., P. Roscoe, and G. M. Feinman. 2014. Cooperation and collective action in the cultural evolution of complex societies. Journal of Archaeological Method and Theory 21:98-133. http://dx.doi.org/10.1007/s10816-012-9147-2

Cash, D. W., W. N. Adger, F. Berkes, P. Garden, L. Lebel, P. Olsson, L. Pritchard, and O. Young. 2006. Scale and cross-scale dynamics: governance and information in a multilevel world. Ecology and Society 11(2):8. [online] URL: http://www.ecologyandsociety. org/vol11/iss $2 / \operatorname{art} 8 /$

Cavalli-Sforza, L. L., and M. W. Feldman. 1981. Cultural transmission and evolution: a quantitative approach. Princeton University Press, Princeton, New Jersey, USA.

Choi, J.-K. and S. Bowles. 2007. The coevolution of parochial altruism and war. Science 318:636-640. http://dx.doi.org/10.1126/ science. 1144237

Colding, J., T. Elmqvist, and P. Olsson. 2003. Living with disturbance: building resilience in social-ecological systems. Pages 163-185 in F. Berkes, J. Colding, and C. Folke, editors. Navigating social-ecological systems: building resilience for complexity and change. Cambridge University Press, Cambridge, UK. http://dx. doi.org/10.1017/cbo9780511541957.011

Costopoulos, A., and M. W. Lake, editors. 2010. Simulating change: archaeology into the twenty-first century. University of Utah Press, Salt Lake City, Utah, USA.

Coultas, J. C. 2004. When in Rome ... an evolutionary perspective on conformity. Group Processes \& Intergroup Relations 7:317-331. http://dx.doi.org/10.1177/1368430204046141

Cumming, G. S., D. H. M. Cumming, and C. L. Redman. 2006. Scale mismatches in social-ecological systems: causes, consequences, and solutions. Ecology and Society 11(1):14. [online] URL: http://www.ecologyandsociety.org/vol11/iss1/ $\underline{\operatorname{art} 14 l}$

DeFries, R., A. Hansen, A. C. Newton, and M. C. Hansen. 2005. Increasing isolation of protected areas in tropical forests over the past twenty years. Ecological Applications 15:19-26. http://dx.doi. org/10.1890/03-5258

Demps, K., F. Zorondo-Rodriguez, C. Garcia, and V. ReyesGarcía. 2012. Social learning across the life cycle: cultural knowledge acquisition for honey collection among the Jenu Kuruba, India. Evolution \& Human Behavior 33:460-470. http:// dx.doi.org/10.1016/j.evolhumbehav.2011.12.008

Dietz, T., E. Ostrom, and P. C. Stern. 2003. The struggle to govern the commons. Science 302:1907-1912. http://dx.doi.org/10.1126/ science. 1091015 
Fehr, E., U. Fischbacher, and S. Gächter. 2002. Strong reciprocity, human cooperation, and the enforcement of social norms. Human Nature 13:1-25. http://dx.doi.org/10.1007/s12110-002-1012-7

Fehr, E., and S. Gächter. 2002. Altruistic punishment in humans. Nature 415:137-140. http://dx.doi.org/10.1038/415137a

Fernández-Llamazares, Á., I. Díaz-Reviriego, M. Guèze, M. Cabeza, A. Pyhälä, and V. Reyes-García. 2016. Local perceptions as a guide for the sustainable management of natural resources: empirical evidence from a small-scale society in Bolivian Amazonia. Ecology and Society 21(1):2. http://dx.doi. org/10.5751/ES-08092-210102

Fischer, J., G. D. Peterson, T. A. Gardner, L. J. Gordon, I. Fazey, T. Elmqvist, A. Felton, C. Folke, and S. Dovers. 2009. Integrating resilience thinking and optimisation for conservation. Trends in Ecology \& Evolution 24:549-554. http://dx.doi.org/10.1016/j. tree.2009.03.020

Fletcher, J. A., and M. Zwick. 2007. The evolution of altruism: game theory in multilevel selection and inclusive fitness. Journal of Theoretical Biology 245:26-36. http://dx.doi.org/10.1016/j. jtbi.2006.09.030

Folke, C. 2006. Resilience: the emergence of a perspective for social-ecological systems analyses. Global Environmental Change 16:253-267. http://dx.doi.org/10.1016/j.gloenvcha.2006.04.002

Fotheringham, A. S., C. Brunsdon, and M. Charlton. 2010. Qualitative geography. Perspectives on spatial data analysis. SAGE, London, UK.

Gibson, C. C., E. Ostrom, and T. K. Ahn. 2000. The concept of scale and the human dimensions of global change: a survey. Ecological Economics 32:217-239. http://dx.doi.org/10.1016/ S0921-8009(99)00092-0

Gintis, H. 2000. Strong reciprocity and human sociality. Journal of Theoretical Biology 206:169-179. http://dx.doi.org/10.1006/ jtbi.2000.2111

Gowdy, J., and L. Krall. 2013. The ultrasocial origin of the Anthropocene. Ecological Economics 95:137-147. http://dx.doi. org/10.1016/j.ecolecon.2013.08.006

Gunderson, L. H., and C. S. Holling. 2002. Panarchy: understanding transformations in human and natural systems, Island Press, Washington, D.C., USA.

Gurven, M., H. Kaplan, and M. Gutierrez. 2006. How long does it take to become a proficient hunter? Implications for the evolution of extended development and long life span. Journal of Human Evolution 51(5):454-470. http://dx.doi.org/10.1016/j. 迆ol.2006.05.003

Henrich, J. 2001. Cultural transmission and the diffusion of innovations: adoption dynamics indicate that biased cultural transmission is the predominate force in behavioral change. American Anthropologist 103:992-1013. http://dx.doi.org/10.1525/ aa.2001.103.4.992

Henrich, J. 2004. Cultural group selection, coevolutionary processes and large-scale cooperation. Journal of Economic Behavior \& Organization 53:3-35. http://dx.doi.org/10.1016/ $\underline{\text { s0167-2681(03)00094-5 }}$
Henrich, J., and R. Boyd. 1998. The evolution of conformist transmission and the emergence of between-group differences. Evolution \& Human Behavior 19:215-241. http://dx.doi. org/10.1016/S1090-5138(98)00018-X

Herrmann, P. A., C. H. Legare, P. L. Harris, and H. Whitehouse. 2013. Stick to the script: the effect of witnessing multiple actors on children's imitation. Cognition 129:536-543. http://dx.doi. org/10.1016/j.cognition.2013.08.010

Holdschlag, A., and B. M. W. Ratter. 2013. Multiscale system dynamics of humans and nature in the Bahamas: perturbation, knowledge, panarchy and resilience. Sustainability Science 8:407-421. http://dx.doi.org/10.1007/s11625-013-0216-6

Holland, J. H. 1992. Complex adaptive systems. Daedalus 121 (1):17-30.

Huanca, T. 2008. Tsimane' oral tradition, landscape, and identity in tropical forest. Imprenta Wagui, La Paz, Bolivia.

Ibáñez, J. J., D. Ortega, D. Campos, L. Khalidi, and V. Méndez. 2015. Testing complex networks of interaction at the onset of the Near Eastern Neolithic using modelling of obsidian exchange. Journal of the Royal Society: Interface 12:20150210. http://dx.doi. org/10.1098/rsif.2015.0210

Kandler, A., R. Unger, and J. Steele. 2010. Language shift, bilingualism and the future of Britain's Celtic languages. Philosophical Transactions of the Royal Society B: Biological Sciences 365:3855-3864. http://dx.doi.org/10.1098/rstb.2010.0051

Kitano, H. 2002. Systems biology: a brief overview. Science 295:1662-1664. http://dx.doi.org/10.1126/science.1069492

Kohler, T. A., and G. J. Gummerman, editors. 2001. Dynamics of human and primate societies: agent-based modeling of social and spatial processes. Oxford University Press, Oxford, UK.

Lake, M. W. 2014. Trends in archaeological simulation. Journal of Archaeological Method and Theory 21(2):258-287. http://dx. doi.org/10.1007/s10816-013-9188-1

Lake, M. W., and E. R. Crema. 2012. The cultural evolution of adaptive-trait diversity when resources are uncertain and finite. Advances in Complex Systems 15:1150013. http://dx.doi. org/10.1142/s0219525911003323

Lansing, J. S. 2003. Complex adaptive systems. Annual Review of Anthropology 32:183-204. http://dx.doi.org/10.1146/annurev. anthro.32.061002.093440

Lansing, J. S. 2006. Perfect order: recognizing complexity in Bali. Princeton University Press, Princeton, New Jersey, USA.

Laurance, W. F., D. C. Useche, J. Rendeiro, M. Kalka, C. J. A. Bradshaw, S. P. Sloan, S. G. Laurance, M. Campbell, K. Abernethy, P. Alvarez, et al. 2012. Averting biodiversity collapse in tropical forest protected areas. Nature 489:290-294. http://dx. doi.org/10.1038/nature11318

Liu, J., T. Dietz, S. R. Carpenter, M. Alberti, C. Folke, E. Moran, A. N. Pell, P. Deadman, T. Kratz, J. Lubchenco, E. Ostrom, Z. Ouyang, W. Provencher, C. L. Redman, S. H. Schneider, and W. W. Taylor. 2007. Complexity of coupled human and natural systems. Science 317:1513-1516. http://dx.doi.org/10.1126/ science. 1144004 
Markofsky, S., A. Ninfo, A. Balbo, F. C. Conesa, and M. Madella. 2016. An investigation of local scale human/landscape dynamics in the endorheic alluvial fan of the Murghab River, Turkmenistan. Quaternary International, in press. http://dx.doi.org/10.1016/j. quaint.2016.01.006

Mazoyer, M. and L. Roudart. 2006. A history of world agriculture. From the Neolithic Age to the current crisis. EarthScan, London, UK.

McDade, T. W., V. Reyes-García, P. Blackinton, S. Tanner, T. Huanca, and W. R. Leonard. 2007. Ethnobotanical knowledge is associated with indices of child health in the Bolivian Amazon. Proceedings of the National Academy of Sciences of the United States of America 104:6134-6139. http://dx.doi.org/10.1073/ pnas.0609123104

Meentemeyer, V., and E. O. Box. 1987. Scale effects in landscape studies. Pages 15-34 in M. G. Turner, editor. Landscape heterogeneity and disturbance. Springer-Verlag, New York, New York, USA. http://dx.doi.org/10.1007/978-1-4612-4742-5 2

Mesoudi, A. 2008. Foresight in cultural evolution. Biology \& Philosophy 23:243-255. http://dx.doi.org/10.1007/s10539-007-9097-3

Michod, R. E., and M. D. Herron. 2006. Cooperation and conflict during evolutionary transitions in individuality. Journal of Evolutionary Biology 19:1406-1409. http://dx.doi.org/10.1111/ j.1420-9101.2006.01142.x

Mwangi, E., and A. Wardell. 2012. Multi-level governance of forest resources. International Journal of the Commons 6:79-103. http://dx.doi.org/10.18352/ijc.374

Nelson, D. R., W. N. Adger, and K. Brown. 2007. Adaptation to environmental change: contributions of a resilience framework. Annual Review of Environment and Resources 32:395-419. http:// dx.doi.org/10.1146/annurev.energy.32.051807.090348

Olson, M. 1965. The logic of collective action. Harvard University Press, Cambridge, Massachusetts, USA.

Ostrom, E. 2010. Beyond markets and states: polycentric governance of complex economic systems. American Economic Review 100:641-672. http://dx.doi.org/10.1257/aer.100.3.641

Ostrom, V. 1999. Polycentricity (part 1). Pages 52-74 in M. D. McGinnis, editor. Polycentricity and local public economies: readings from the workshop in political theory and policy analysis. University of Michigan Press, Ann Arbor, Michigan, USA.

Parker, D. C., S. M. Manson, M. A. Janssen, M. J. Hoffmann, and P. Deadman. 2003. Multi-agent systems for the simulation of land-use and land-cover change: a review. Annals of the Association of American Geographers 93:314-337. http://dx.doi. org/10.1111/1467-8306.9302004

Perreault, C. 2012. The pace of cultural evolution. PLoS ONE 7: e45150. http://dx.doi.org/10.1371/journal.pone.0045150

Quave, C. L., and A. Pieroni. 2015. A reservoir of ethnobotanical knowledge informs resilient food security and health strategies in the Balkans. Nature Plants 1:1-6. http://dx.doi.org/10.1038/ nplants.2014.21

Reid, W. V., F. Berkes, T. Wilbanks, and C. Capistriano. 2006. Bridging scales and local knowledge in assessments. Island Press, Washington D.C., USA.
Reyes-García, V., M. Guèze, I. Diaz-Reviriego, R. Duda, á. Fernández-Llamazares, S. Gallois, L. Napitupulu, M. OrtaMartínez, and A. Pyhälä. In press. The adaptive nature of culture. A cross-cultural analysis of the returns of local environmental knowledge in three indigenous societies. Current Anthropology.

Reyes-García, V., M. Guèze, A. C. Luz, J. Paneque-Gálvez, M. J. Macìa, M. Orta-Martínez, J. Pino, and X. Rubio-Campillo. 2013. Evidence of traditional knowledge loss among a contemporary indigenous society. Evolution \& Human Behavior 34:249-257. http://dx.doi.org/10.1016/j.evolhumbehav.2013.03.002

Reyes-García, V., J. Paneque-Gálvez, P. Bottazzi, A. C. Luz, M. Guèze, M. J. Macìa, M. Orta-Martínez, and P. Pachecho. 2014. Indigenous land reconfiguration and fragmented institutions: A historical political ecology of the Tsimane' lands (Bolivian Amazon). Journal of Rural Studies 34:282-291. http://dx.doi. org/10.1016/i.jrurstud.2014.02.007

Richerson, P., R. Baldini, A. V. Bell, K. Demps, K. Frost, V. Hillis, S. Mathew, E. K. Newton, N. Narr, L. Newson, C. Ross, P. E. Smaldino, T. M. Waring, and M. Zefferman. 2016. Cultural group selection plays an essential role in explaining human cooperation: a sketch of the evidence. Behavioral and Brain Sciences 39:e30. http://dx.doi.org/10.1017/s0140525x1400106x

Richerson, P., and R. Boyd. 2005. Not by genes alone: how culture transformed human evolution. University of Chicago Press, Chicago, Illinois, USA. http://dx.doi.org/10.7208/

chicago/9780226712130.001.0001

Richerson, P. J., and R. Boyd. 2013. Rethinking paleoanthropology: a world queerer than we supposed. Pages 263-302 in G. Hatfield and H. Pittman, editors. Evolution of mind, brain, and culture. University of Pennsylvania Museum of Archaeology and Anthropology, Philadelphia, Pennsylvania, USA. http://dx.doi.org/10.9783/9781934536605.263

Ruiz-Mallén, I., E. Corbera, D. Calvo-Boyero, V. Reyes-García, and K. Brown. 2015. How do biosphere reserves influence vulnerability and adaptation? Evidence from Latin America. Global Environmental Change 33:87-108. http://dx.doi.org/10.1016/ j.gloenvcha.2015.05.002

Shennan, S., S. S. Downey, A. Timpson, K. Edinborough, S. Colledge, T. Kerig, K. Manning, and M. G. Thomas. 2013. Regional population collapse followed initial agriculture booms in mid-Holocene Europe. Nature Communications 4:2486. http:// dx.doi.org/10.1038/ncomms3486

Skoglund, P., H. Malmstrom, M. Raghavan, J. Stora, P. Hall, E. Willerslev, M. T. P. Gilbert, A. Gõtherstrom, and M. Jakobsson. 2012. Origins and genetic legacy of Neolithic farmers and huntergatherers in Europe. Science 336:466-469. http://dx.doi. org/10.1126/science.1216304

Smit, B., and J. Wandel. 2006. Adaptation, adaptive capacity and vulnerability. Global Environmental Change 16:282-292. http://dx. doi.org/10.1016/j.gloenvcha.2006.03.008

Smith, E. A., and B. Winterhalder. 1992. Evolutionary ecology and human behavior. Aldine De Gruyter, New York, New York, USA. 
Smith, J. M. 1982. Evolution and the theory of games. Cambridge University Press, Cambridge, UK. http://dx.doi.org/10.1017/ CBO9780511806292

Smith, K., M. L. Kalish, T. L. Griffiths, and S. Lewandowsky. 2008. Introduction. Cultural transmission and the evolution of human behaviour. Philosophical Transactions of the Royal Society B: Biological Sciences 363:3469-3476. http://dx.doi.org/10.1098/ $\underline{\text { rstb. } 2008.0147}$

Sternberg, R., C. Nokes, P. W. Geissler, R. Prince, F. Okatcha, D. A. Bundy, and E. L. Grigorenko. 2001. The relationship between academic and practical intelligence: a case study in Kenya. Intelligence 29:401-418. http://dx.doi.org/10.1016/S0160-2896 (01)00065-4

Traulsen, A., and M. A. Nowak. 2006. Evolution of cooperation by multilevel selection. Proceedings of the National Academy of Sciences of the United States of America 103:10952-10955. http:// dx.doi.org/10.1073/pnas.0602530103

Turchin, P. 2003. Historical dynamics: why states rise and fall. Princeton University Press, Princeton, New Jersey, USA.

Walker, B. H., L. H. Gunderson, A. P. Kinzig, C. Folke, S. R. Carpenter, and L. Schultz. 2006. A handful of heuristics and some propositions for understanding resilience in social-ecological systems. Ecology and Society 11(1):13. [online] URL: http://www. ecologyandsociety.org/vol11/iss1/art13/

Waring, T. M., M. A. Kline, J. S. Brooks, S. H. Goff, J. Gowdy, M. A. Janssen, P. E. Smaldino, and J. Jacquet. 2015. A multilevel evolutionary framework for sustainability analysis. Ecology and Society 20(2):34. http://dx.doi.org/10.5751/ES-07634-200234

Whitehead, H., and P. J. Richerson. 2009. The evolution of conformist social learning can cause population collapse in realistically variable environments. Evolution and Human Behavior 30:261-273. http://dx.doi.org/10.1016/j.

evolhumbehav.2009.02.003

Wurzer, G., K. Kowarik, and H. Reschreiter, editors. 2015. Agentbased modeling and simulation in archaeology (Advances in Geographic Information Science). Springer, Cham, Switzerland. 